\title{
MYC DNA Methylation in Prostate Tumor Tissue is Associated with Gleason Score
}

\author{
Kathryn Hughes Barry ${ }^{1,2, *}$, Kareshma Mohanty ${ }^{1}$, Patricia A. Erickson ${ }^{1}$, Difei Wang ${ }^{3}$, Jianxin Shi ${ }^{3}$, Gary Rose ${ }^{4}$, \\ Ashley Cellini ${ }^{5}$, Kimberly Clark ${ }^{5}$, Nicholas Ambulos, Jr. ${ }^{2,6}$, Jing Yin ${ }^{2,6}$, Liying Yan ${ }^{7}$, Matthew Poulin ${ }^{7}$, \\ Ann Meyer ${ }^{7}$, Yuji Zhang ${ }^{1,2}$, Søren M. Bentzen ${ }^{1,2}$, Allen Burke ${ }^{4}$, Arif Hussain ${ }^{2,8,9}$ and Sonja I. Berndt ${ }^{10}$
}

1 Department of Epidemiology and Public Health, University of Maryland School of Medicine, Baltimore, MD 21201, USA; kmohanty@som.umaryland.edu (K.M.); patricia.erickson@som.umaryland.edu (P.A.E.); yuzhang@som.umaryland.edu (Y.Z.); sbentzen@som.umaryland.edu (S.M.B.)

2 Program in Oncology, University of Maryland Greenebaum Comprehensive Cancer Center, Baltimore, MD 21201, USA; nambulos@som.umaryland.edu (N.A., Jr.); jyin@som.umaryland.edu (J.Y.); ahussain@som.umaryland.edu (A.H.)

3 Biostatistics Branch, Division of Cancer Epidemiology and Genetics, National Cancer Institute, Rockville, MD 20850, USA; difei.wang@nih.gov (D.W.); jianxin.shi@nih.gov (J.S.)

4 Department of Pathology, University of Maryland School of Medicine, Baltimore, MD 21201, USA; garysamuelrose@gmail.com (G.R.); aburke@umm.edu (A.B.)

5 Pathology Biorepository Shared Service, University of Maryland Greenebaum Comprehensive Cancer Center, Baltimore, MD 21201, USA; acellini@som.umaryland.edu (A.C.); kimberly.clark@som.umaryland.edu (K.C.)

6 Department of Microbiology and Immunology, University of Maryland School of Medicine, Baltimore, MD 21201, USA

7 EpigenDx, Inc., Hopkinton, MA 01748, USA; lyan@epigendx.com (L.Y.); mpoulin@epigendx.com (M.P.); ameyer@epigendx.com (A.M.)

8 Department of Medicine, University of Maryland School of Medicine, Baltimore, MD 21201, USA

9 Baltimore Veterans Administration Medical Center, Baltimore, MD 21201, USA

10 Occupational and Environmental Epidemiology Branch, Division of Cancer Epidemiology and Genetics, National Cancer Institute, Rockville, MD 20850, USA; berndts@mail.nih.gov

check for

updates

Citation: Barry, K.H.; Mohanty, K.; Erickson, P.A.; Wang, D.; Shi, J.; Rose, G.; Cellini, A.; Clark, K.; Ambulos, N., Jr.; Yin, J.; et al. MYC DNA Methylation in Prostate Tumor Tissue is Associated with Gleason Score. Genes 2021, 12, 12. https://doi.org/10.3390/genes12010012

Received: 28 September 2020 Accepted: 11 December 2020 Published: 24 December 2020

Publisher's Note: MDPI stays neutral with regard to jurisdictional claims in published maps and institutional affiliations.

Copyright: () 2020 by the authors. Licensee MDPI, Basel, Switzerland. This article is an open access article distributed under the terms and conditions of the Creative Commons Attribution (CC BY) license (https:/ / creativecommons.org/ licenses/by/4.0/).
* Correspondence: kbarry@som.umaryland.edu; Tel.: +1-410-706-1208

\begin{abstract}
Increasing evidence suggests a role of epigenetic mechanisms at chromosome 8q24, an important cancer genetic susceptibility region, in prostate cancer. We investigated whether MYC DNA methylation at 8q24 (six CpG sites from exon 3 to the $3^{\prime}$ UTR) in prostate tumor was associated with tumor aggressiveness (based on Gleason score, GS), and we incorporated RNA expression data to investigate the function. We accessed radical prostatectomy tissue for 50 Caucasian and 50 African American prostate cancer patients at the University of Maryland Medical Center, selecting an equal number of GS 6 and GS 7 cases per group. MYC DNA methylation was lower in tumor than paired normal prostate tissue for all six CpG sites (median difference: -14.74 to -0.20 percentage points), and we observed similar results for two nearby sites in The Cancer Genome Atlas $(p<0.0001)$. We observed significantly lower methylation for more aggressive (GS 7) than less aggressive (GS 6) tumors for three exon 3 sites (for CpG 212 (chr8:128753145), GS 6 median $=89.7 \%$; GS 7 median $=85.8 \% ; p$-value $\left.=9.4 \times 10^{-4}\right)$. MYC DNA methylation was not associated with $M Y C$ expression, but was inversely associated with PRNCR1 expression after multiple comparison adjustment $(q$-value $=0.04)$. Findings suggest that prostate tumor $M Y C$ exon 3 hypomethylation is associated with increased aggressiveness.
\end{abstract}

Keywords: aggressive disease; DNA methylation; Gleason score (GS); MYC; non-coding RNAs (ncRNAs); prostate cancer; RNA expression; tumor tissue biomarkers

\section{Introduction}

Chromosome 8q24 has been established as an important region in the genetic susceptibility to prostate cancer [1-11], particularly among men of African ancestry, where addi- 
tional susceptibility single nucleotide polymorphisms (SNPs) have been discovered that are monomorphic in other populations [10] and explain a greater proportion of familial risk [12]. The underlying mechanisms of susceptibility due to this region are still poorly understood. The 8q24 locus has been traditionally described as a gene desert, with the nearest prostate cancer susceptibility SNP located about $200 \mathrm{~kb}$ upstream of the oncogene MYC. However, this terminology is somewhat misleading, since there are several other genes and non-coding RNAs (ncRNAs) located at 8q24. MYC encodes a transcription factor that regulates genes involved in cell growth, differentiation and apoptosis. MYC is commonly overexpressed in prostate tumor tissue and has long been thought to play a role in prostate cancer, and particularly with regard to prostate cancer progression [13]. Several other genes and ncRNAs at 8q24, such as POU5F1B (previously thought to be a pseudogene), PRNCR1, CASC11 and CCAT2, have also been shown to be overexpressed in prostate cancer [14-17] and may also play a role in the development or progression of prostate cancer.

There is growing evidence for a role of epigenetic mechanisms at chromosome 8q24 in prostate cancer based on the identification of gene regulatory elements at this locus [18], as well as long-range tissue-specific interactions between 8q24 cancer susceptibility loci and MYC $[19,20]$. Expanding on these findings, Du and colleagues examined physical interactions across the genome for several $8 \mathrm{q} 24$ cancer susceptibility regions using a chromosome conformation capture (3C)-based, multi-target sequencing technology in cell lines for a variety of cancers (including prostate) and found frequent interactions with MYC as well as other intra- and inter-chromosomal targets; other common intra-chromosomal targets included PVT1, FAM84B and GSDMC [21]. The authors also observed an enrichment of interactions with genes in important cancer pathways such as Wnt signaling. Another study investigating genome-wide physical interactions using circularized chromosome conformation capture $(4 \mathrm{C})$ coupled with next-generation sequencing for an 8q24 enhancer region also identified interactions with MYC, FAM84B and GSDMC, among other genes [22]. These findings suggest that the $8 \mathrm{q} 24$ locus may function as a regulatory hub for a variety of gene targets in important cancer pathways [21].

A major component of the epigenetic code is DNA methylation, which involves the addition of a methyl group (typically to a cytosine base located $5^{\prime}$ to a guanine, i.e., CpG site) and is thought to influence carcinogenesis by affecting gene expression or genetic stability [23]. Previous studies have demonstrated the importance of DNA methylation alterations in prostate cancer, both early in prostate cancer development and also with regard to prostate cancer progression [24-27]. In previous work from our group, we reported an increased risk of aggressive prostate cancer associated with higher peripheral blood DNA methylation in MYC exon 3 in a large prospective study using pre-diagnostic blood samples, which persisted after adjustment for established 8q24 prostate cancer susceptibility loci [28].

In the present study, our primary aim was to investigate whether MYC exon 3 DNA methylation in prostate tumor tissue was associated with tumor aggressiveness based on Gleason score (GS), an intermediate prognostic marker for prostate cancer [29]. Exon 3 in MYC is highly conserved across species and, interestingly, hypomethylation at MYC exon 3 was observed in human myeloma cell lines compared to normal lymphocytes [30] and correlated with progression from normal tissue to metastatic disease in colorectal tissue [31]. As a secondary aim, we sought to explore the potential downstream consequences of prostate tumor MYC DNA methylation by evaluating associations with RNA expression for $M Y C$ and other nearby genes and ncRNAs in prostate tumor tissue. As another secondary aim, we investigated whether the association between MYC DNA methylation and GS varied by race (African American vs. Caucasian) given striking disparities in prostate cancer outcomes by race [32] and growing evidence for a role of biological differences in tumor [33-35].

Our findings indicated lower MYC DNA methylation in prostate tumor compared to paired normal prostate tissue samples for all $\mathrm{CpG}$ sites evaluated, suggesting that these may 
represent somatic alterations in prostate tissue. In addition, we observed significantly lower MYC DNA methylation at three exon 3 CpG sites in more aggressive (GS 7) compared to less aggressive (GS 6) tumors, and we observed a similar pattern for another exon $3 \mathrm{CpG}$ site that approached statistical significance. We observed some evidence of a stronger association between MYC DNA methylation and GS for African American than Caucasian men for one of the CpG sites that showed a significant overall association with GS. Incorporation of RNA expression data indicated an inverse association between prostate tumor MYC DNA methylation and PRNCR1 expression in tumor tissue. Additional research is needed to replicate these findings and further investigate the potential role of MYC DNA methylation in aggressive prostate cancer using experimental laboratory designs.

\section{Materials and Methods}

\subsection{Study Samples}

We accessed archival formalin-fixed, paraffin-embedded (FFPE) tumor and normal prostate tissue samples from 50 Caucasian and 50 African American prostate cancer patients who underwent radical prostatectomy at the University of Maryland Medical Center. For each race group, we selected 25 men with GS 7 and 25 men with GS 6 disease to allow for separate evaluation of the association between MYC DNA methylation and GS by race; the study workflow is presented in Figure 1. We did not include men with GS 8 or higher due to relatively small numbers available for analysis. We systematically selected the most recent samples available. This study was approved by the IRB at the University of Maryland, Baltimore (HP-00074942, most recent approval date: 7 July 2020). We obtained a waiver of informed consent as part of the approved IRB protocol. The data presented in this paper will be made freely available upon request.

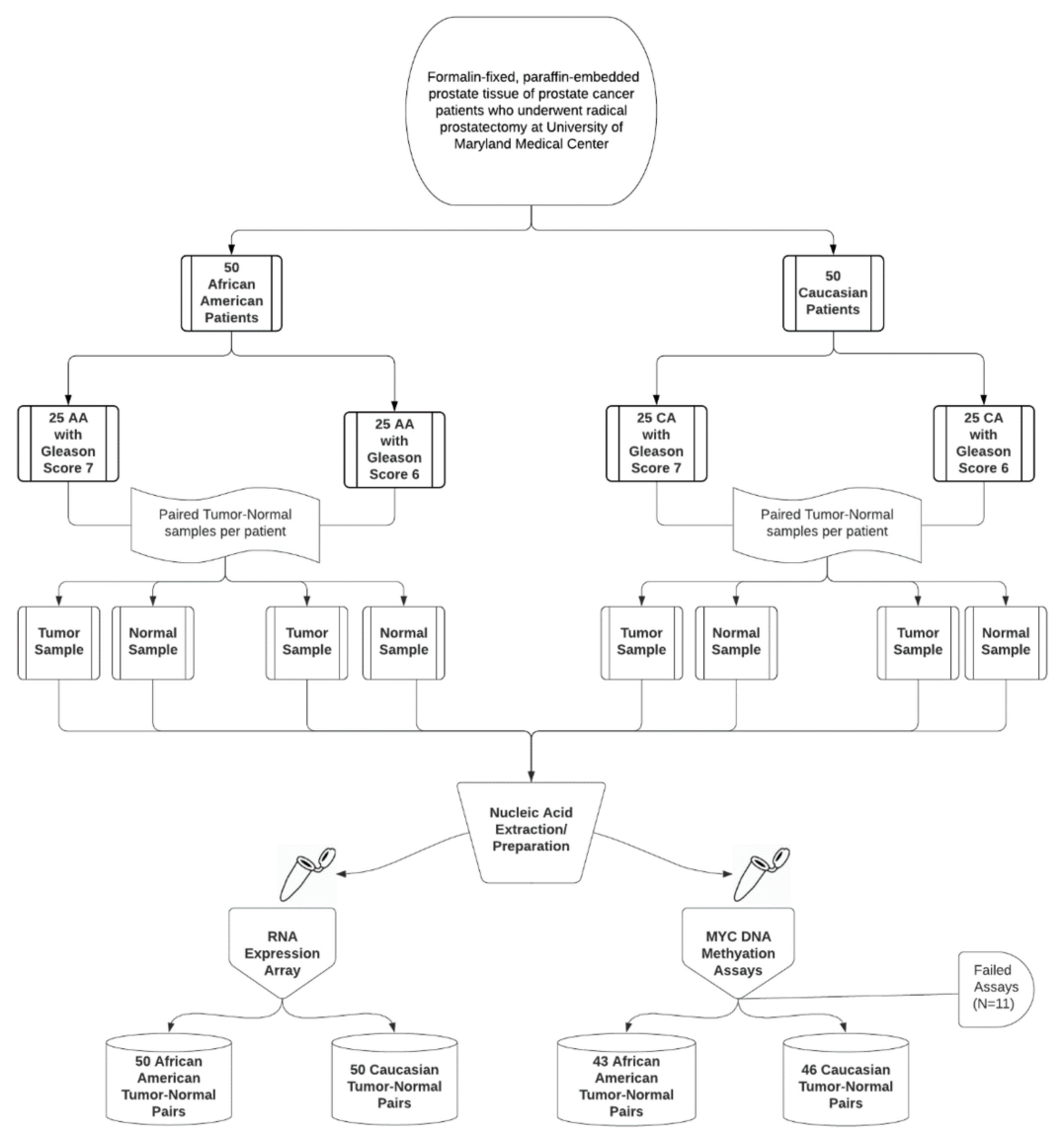

Figure 1. Study workflow for the University of Maryland samples. Abbreviations: AA, African American; CA, Caucasian. 
We identified the most representative tumor block and the most representative normal block from the available FFPE radical prostatectomy tissue for each patient. Based on an H\&E slide, we circled $\sim 2 \mathrm{~mm}$ tumor regions ( $\geq 75 \%$ purity) and $\sim 2 \mathrm{~mm}$ normal regions for nucleic acid extraction, then cut six unstained double-thickness slides (10 $\mu \mathrm{m})$ per sample, with four used for the DNA methylation assays and two used for the RNA expression assays from the same circled regions. For patients with a GS of 7, we preferentially targeted regions with a Gleason pattern 4 to provide greater contrast with our comparison group (patients with GS of 6, i.e., who typically have Gleason pattern 3 only). We cut additional slides from the tumor and normal samples to serve as replicate samples for quality control for the DNA methylation assays $(n=3)$. We also cut additional tumor and normal slides to serve as quality control replicates for the RNA expression assays $(n=5)$.

\subsection{Nucleic Acid Extraction/Preparation and RNA Quality Assessment}

In preparation for the DNA methylation assays, the University of Maryland FFPE samples were sent to EpigenDx, Inc. (Hopkinton, MA, USA), where direct bisulfite treatment was performed on digested FFPE tissue. Specifically, FFPE samples were deparaffinized with Histochoice clearing reagent and dehydrated with $100 \%$ ethanol. Samples were then digested with Proteinase $\mathrm{K}$ in a $1 X$ digestion buffer and $20 \mathrm{uL}$ were directly bisulfite treated using the Zymo Research EZ DNA Methylation Direct Bisulfite Kit. For the RNA expression assays, RNA was extracted at the University of Maryland, Baltimore using Qiagen's RNEasy FFPE kit. Quantitative analysis was performed using both a ThermoFisher NanoDrop and an Agilent Technology's BioAnalyzer. In addition, we evaluated the quality of the RNA using an RNA quality assessment kit from ThermoFisher. Briefly, this approach involved calculating the difference in quantification cycles $(\mathrm{Cq})$, i.e., delta $\mathrm{Cq}$, between each study sample and high-quality RNA controls (HeLa cells); lower delta Cq values correlate with higher quality RNA (ThermoFisher, Carlsbad, CA, USA).

\subsection{MYC DNA Methylation Assays}

We conducted targeted pyrosequencing assays on bisulfite-treated DNA from the University of Maryland samples to measure DNA methylation at six CpG sites spanning from MYC exon 3 to the $3^{\prime}$ UTR (GRCh37/hg19 coordinates: chr8:128753145-chr8:128753221; the sites were labeled as CpG 212-CpG 217 for ease of referencing) (EpigenDx, Inc., Hopkinton, MA, USA). Specifically, five of the CpG sites (212-216) were located in exon 3, and the remaining CpG site (217) was located in the $3^{\prime}$ UTR for MYC. The bisulfite conversion step and pyrosequencing assays have been described previously [28,36]. The target sequences for the specific assays run in this study (ADS3573-FS and ADS3573-FS2) are given in Table A1 in Appendix A. There were 11 patients for whom the assays failed in the present study, and thus our analyses using the DNA methylation data were restricted to the remaining 43 African American and 46 Caucasian men $(n=89)$. We computed coefficients of variation (CVs) for each $\mathrm{CpG}$ site based on the three participants with replicate QC samples (i.e., three pairs of tumor samples and three pairs of normal samples). The average CV across all six CpG sites was 2.7\% for the normal tissue pairs and $3.4 \%$ for the tumor tissue pairs.

\subsection{RNA Expression Data}

We obtained RNA expression data from the University of Maryland samples using the Human Clariom D ${ }^{\mathrm{TM}}$ array (ThermoFisher, Carlsbad, CA, USA), which covers 138,745 transcript cluster IDs (TCs). We used the UCSC Genome Browser to identify genes and ncRNAs within $1 \mathrm{Mb}$ either upstream or downstream of $M Y C$ based on GRCh37/hg19 coordinates for MYC (i.e., chr8:128748315-128753680). We then used the NetAff ${ }^{\mathrm{TM}}$ tool [37] to identify the TCs that corresponded to MYC and the other genes/ncRNAs of interest in our array data. Of the 33 genes/ncRNAs in the region of interest, nine were not covered on the Clariom D array (SRMP1P1, AC020688.1, JX003871, BC106081, DQ515899, AC108714.1, BC042052, HV975509 and AC103705.1). Based on the available genes/ncRNAs, we identified 
a total of 22 TCs for analysis. We performed SST-RMA normalization and log2 transformation of the expression data using TAC v.4.0 software (ThermoFisher, Carlsbad, CA, USA). Analyses of the RNA expression data by tumor/normal status were conducted in 100 tumor-normal pairs. Analyses of RNA expression by GS were done using 100 tumor samples. Analyses of prostate tumor MYC DNA methylation in relation to RNA expression in prostate tumor tissue were limited to the 89 tumor samples with DNA methylation data. We computed CVs for each TC of interest based on the five participants with replicate QC samples (i.e., five pairs of tumor samples and five pairs of normal samples). The average $\mathrm{CV}$ across the 22 TCs was $6.8 \%$ for the normal tissue pairs and $8.3 \%$ for the tumor tissue pairs.

\subsection{The Cancer Genome Atlas (TCGA) DNA Methylation Data}

We incorporated DNA methylation array data from the TCGA-PRAD cohort (498 primary prostate tumor samples) to evaluate two additional MYC exon 3 CpG sites nearby $(<0.2 \mathrm{~kb})$ the $\mathrm{CpG}$ sites evaluated in the University of Maryland samples in relation to tumor/normal status and GS among the tumor samples. We downloaded the TCGA-PRAD Illumina Infinium HumanMethylation450 (HM450) BeadArray level 3 data from https:/ / gdac.broadinstitute.org (data version: 2016_10_28) for all 498 PRAD primary tumor and 50 normal samples. We first extracted the $\beta$ values of these two CpG probes (cg00163372 and cg08526705) for the 50 tumor-normal paired samples (47 Caucasian and three African American men). In addition, we also extracted the data for all tumor samples with GS $6(n=45)$ and GS $7(n=248)$ for DNA methylation comparisons by GS. We computed the median $\beta$ values and the interquartile range (IQR) for the tumor and normal tissue samples, and separately by GS for the tumor samples. The $\beta$ values (ranging from 0 to 1 ), widely used to measure the methylation level, were converted to percentages to be comparable to the results for the University of Maryland samples.

\subsection{Statistical Analysis}

Analyses were conducted in SAS Studio 3.8 and R Studio (version 3.6.1). We evaluated Spearman correlations in \% DNA methylation for MYC CpG-CpG pairings, separately for tumor and normal samples. We used Wilcoxon signed-rank tests to assess differential DNA methylation and RNA expression between paired tumor and normal prostate tissue samples from the same individual. We used Wilcoxon rank sum tests to compare DNA methylation and RNA expression between the GS 6 and GS 7 groups using tumor tissue. We used logistic regression models to compute odds ratios (OR) and 95\% confidence intervals (95\% CI) for the association between decreasing CpG site DNA methylation in prostate tumor tissue (modeled continuously) and GS (7 vs. 6) overall and separately by race (African American and Caucasian). Additional adjustment for age at surgery, year of surgery or imputed immune cell distribution in the tumor tissue from CIBERSORTx software [38] did not appreciably alter the results, and thus these variables were not adjusted in the final models. We evaluated the interaction between each CpG site and race by including $\mathrm{CpG}$ site $\times$ race as a cross-product term in the model and testing for significance. We also used a similar approach to assess the interaction between each TC and race with regard to GS. We considered an interaction $p$-value $<0.20$ as noteworthy (even if not statistically significant). For all analyses, we defined statistical significance as a $p$-value $<0.05$.

We performed principal components analysis to assess potential clustering patterns in the RNA expression data by tissue type (tumor/normal), array run, RNA extraction batch, Positive vs. Negative Area Under the Curve (AUC), which is a QC measure computed by the TAC software, RNA quality (based on delta $\mathrm{Cq}$ ) and covariates including age at surgery and year of surgery. We did not observe much evidence of clustering for most of the factors examined except for array run, Positive vs. Negative AUC and RNA quality (data not presented).

To assess the association between MYC DNA methylation and RNA expression in tumor tissue, we ran separate linear regression models for each of the 22 TCs of interest 
(dependent variable) in relation to each CpG site (independent variable). We computed q-values reflecting the false discovery rate after multiple comparison adjustment (22 models for each CpG site) using the Benjamini and Hochberg method [39]. Given the clustering in the RNA expression data noted above, we assessed the impact of additional adjustment for array run, Positive vs. Negative AUC and RNA quality (as well as age at surgery and year of surgery) in our models; however, these variables did not appreciably alter the results, and thus were not adjusted in the final models. As a sensitivity analysis, we also ran additional linear regression models restricted to the samples of highest quality (Positive vs. Negative AUC > 0.7) to ensure that the results were not unduly influenced by sample quality.

\section{Results}

\subsection{Study Population Characteristics}

Among the 89 prostate cancer patients from the University of Maryland Medical Center who had available MYC DNA methylation data for analysis, age at radical prostatectomy ranged from $42-75$ years, with a median age of 58 years; the distribution of age at diagnosis was similar to the age at surgery (Table 1). Year of surgery ranged from 2001 to 2017. Our study sample was about evenly divided between Caucasian and African American men (i.e., $52 \%$ and $48 \%$, respectively) and between men with GS 6 and those with GS 7 tumors ( $45 \%$ and $55 \%$, respectively) based on our study design. Of the 49 men with GS 7 tumors, a greater proportion had a Gleason pattern of $3+4$ than $4+3$ (Table 1). Most men $(67 \%)$ had a pathologic tumor stage (pT stage) of $2,25 \%$ had a pT stage of 3 and $8 \%$ had missing pT stage information. Of the patients with known nodal involvement, $95 \%$ were classified as N0 as expected for this radical prostatectomy population. The median preoperative prostate-specific antigen (PSA) concentration was $6.2 \mathrm{ng} / \mathrm{mL}$ (interquartile range (IQR): 4.8, 8.0). The men with GS 6 tumors were generally similar to those with GS 7 tumors with respect to demographic characteristics, except that the GS 6 patients tended to have radical prostatectomy in earlier years (Table 1).

Table 1. Characteristics of radical prostatectomy prostate cancer patients at the University of Maryland Medical Center who had available MYC DNA methylation data, overall and by total GS.

\begin{tabular}{|c|c|c|c|}
\hline Characteristic & Overall $(n=89)$ & GS $6(n=40)$ & GS $7(n=49)$ \\
\hline Age at surgery, median (range) & $58(42,75)$ & $56.5(42,72)$ & $58(47,75)$ \\
\hline Age at diagnosis, median (range) & $57(42,75)$ & $56(42,72)$ & $57.5(47,75)$ \\
\hline \multicolumn{4}{|l|}{ Surgery year, $n$ (col \%) } \\
\hline 2001-2009 & $18(20.2)$ & $18(45.0)$ & $0(0.0)$ \\
\hline 2010-2017 & $71(79.8)$ & $22(55.0)$ & $49(100.0)$ \\
\hline \multicolumn{4}{|l|}{ Race, $n$ (col \%) } \\
\hline Caucasian & $46(51.7)$ & $21(52.5)$ & $25(51.0)$ \\
\hline African American & $43(48.3)$ & $19(47.5)$ & $24(49.0)$ \\
\hline \multicolumn{4}{|l|}{ Gleason pattern, $n$ (col \%) } \\
\hline $3+3$ & $40(44.9)$ & $40(100.0)$ & $0(0.0)$ \\
\hline $3+4$ & $35(39.3)$ & $0(0)$ & $35(71.4)$ \\
\hline $4+3$ & $14(15.7)$ & $0(0)$ & $14(28.6)$ \\
\hline \multicolumn{4}{|l|}{ pT stage, $n($ col \%) } \\
\hline 2 & $60(67.4)$ & $29(72.5)$ & $31(63.3)$ \\
\hline $3 a$ & $11(12.4)$ & $2(5.0)$ & $9(18.4)$ \\
\hline $3 b$ & $7(7.9)$ & $1(2.5)$ & $6(12.2)$ \\
\hline 3-not specified & $4(4.5)$ & $1(2.5)$ & $3(6.1)$ \\
\hline Unknown & $7(7.9)$ & 7 (17.5) & $0(0.0)$ \\
\hline
\end{tabular}


Table 1. Cont.

\begin{tabular}{lccc}
\hline Characteristic & Overall $(n=89)$ & GS 6 $(n=40)$ & GS 7 ( $n=49)$ \\
\hline pN status, $n$ (col \%) & & & \\
N0 & $55(61.8)$ & $15(37.5)$ & $40(81.6)$ \\
N1 & $3(3.4)$ & $0(0.0)$ & $3(6.1)$ \\
Unknown & $31(34.8)$ & $25(62.5)$ & $6(12.2)$ \\
\hline PSA $(\mathrm{ng} / \mathrm{mL})$, median (IQR) & $6.2(4.8,8.0)$ & $6.2(4.7,7.2)$ & $6.6(5.0,9.0)$ \\
\hline
\end{tabular}

Abbreviations: GS, Gleason score; IQR, interquartile range; $\mathrm{pN}$ status, pathologic nodal involvement; PSA, prostate-specific antigen concentration; $\mathrm{pT}$ stage, pathologic tumor stage.

\subsection{MYC DNA Methylation CpG-CpG Correlations and Prostate Tumor-Normal Differences}

DNA methylation levels at the six MYC CpG sites evaluated in the University of Maryland samples were moderately correlated in tumor tissue (Spearman rho: 0.27 to 0.66 , $p$-value $<0.01$ for all $\mathrm{CpG}$ site pairings). Correlations were less pronounced in the normal tissue samples (Spearman rho: -0.08 to 0.57 ), with fewer results achieving statistical significance at the 0.05 level.

In the normal prostate tissue samples from the University of Maryland, \% DNA methylation tended to be relatively high for the six CpG sites evaluated, with the exception of CpG 217 (chr8:128753221), which was the one CpG site evaluated in the 3' UTR of MYC and which displayed a median of $66.66 \%$ (Table 2). The median \% DNA methylation in the normal samples for the other five CpG sites (located in MYC exon 3) ranged from $83.39 \%$ to $89.72 \%$. When we compared paired tumor and normal prostate tissue samples from the same individual, we observed significantly lower MYC DNA methylation for five of the six CpG sites in the tumor than the normal samples ( $p$-value $<0.05$ ). The sixth CpG site (CpG 212 at chr8: 128753145) displayed a similar pattern, with a borderline significant $p$-value $(p=0.06)$. The median tumor-normal difference in \% DNA methylation for the six CpG sites ranged from -14.74 to -0.20 percentage points (Table 2). Similar results were observed for the two nearby CpG sites evaluated in TCGA, with both sites showing significantly lower methylation in tumor compared to normal samples (median differences of -6.89 and -5.46 percentage points, respectively; Table 2). Median tumor-normal differences in the University of Maryland samples tended to be similar between Caucasian and African American men. The number of African American men with paired tumor and normal tissue in the TCGA dataset was too small $(n=3)$ for meaningful comparison by race. 
Table 2. Tumor-normal prostate tissue differences in \% DNA methylation for MYC CpG sites in the University of Maryland and TCGA samples.

\begin{tabular}{|c|c|c|c|c|}
\hline $\begin{array}{l}\text { CpG Site (GRCH37/hg19 } \\
\text { Coordinate) }\end{array}$ & $\begin{array}{c}\text { Median \% DNA methylation } \\
\text { (IQR) for Normal Prostate } \\
\text { Tissue Samples }\end{array}$ & $\begin{array}{c}\text { Median \% DNA methylation } \\
\text { (IQR) for Prostate Tumor } \\
\text { Tissue Samples }\end{array}$ & $\begin{array}{l}\text { Median Tumor-Normal Difference } \\
\text { in \% DNA Methylation (IQR) }\end{array}$ & Wilcoxon Signed-Rank $p$-Value ${ }^{a}$ \\
\hline \multicolumn{5}{|l|}{$\begin{array}{l}\text { University of Maryland samples } \\
\qquad(n=89 \text { pairs })\end{array}$} \\
\hline CpG 212 (Chr8:128753145) & $88.27(85.32,91.48)$ & $88.29(82.35,91.07)$ & $-0.20(-7.58,2.91)$ & 0.06 \\
\hline CpG 213 (Chr8:128753151) & $85.65(82.00,88.48)$ & $78.72(72.39,84.20)$ & $-7.36(-18.40,0.43)$ & $1.8 \times 10^{-8}$ \\
\hline CpG 214 (Chr8:128753154) & $89.72(87.03,93.23)$ & $86.09(78.82,90.38)$ & $-2.98(-11.38,2.04)$ & $4.9 \times 10^{-5}$ \\
\hline CpG 215 (Chr8:128753187) & $86.65(83.90,89.65)$ & $82.68(79.23,87.12)$ & $-2.84(-9.79,0.67)$ & $1.7 \times 10^{-6}$ \\
\hline CpG 216 (Chr8:128753200) & $83.39(80.67,86.29)$ & $81.41(77.56,85.22)$ & $-1.88(-5.70,2.00)$ & $3.9 \times 10^{-3}$ \\
\hline CpG 217 (Chr8:128753221) & $66.66(60.81,71.15)$ & $49.09(41.30,58.63)$ & $-14.74(-25.53,-6.86)$ & $9.1 \times 10^{-19}$ \\
\hline Across all 6 CpG sites & $83.23(81.77,84.82)$ & $77.40(73.43,81.46)$ & $-4.01(-12.12,1.32)$ & $5.9 \times 10^{-14}$ \\
\hline \multicolumn{5}{|l|}{ TCGA samples ( $n=50$ pairs) } \\
\hline cg00163372 (Chr8:128752987) & $94.52(91.57,95.50)$ & $84.62(78.10,92.01)$ & $-6.89(-16.92,-2.47)$ & $9.4 \times 10^{-7}$ \\
\hline cg08526705 (Chr8:128753028) & $93.01(91.03,94.42)$ & $87.30(80.87,91.82)$ & $-5.46(-13.41,-0.32)$ & $1.3 \times 10^{-5}$ \\
\hline
\end{tabular}

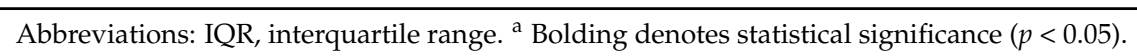




\subsection{MYC DNA Methylation Differences by GS in Prostate Tumor Tissue}

Among the University of Maryland tumor samples, we observed significantly lower MYC DNA methylation for more aggressive tumors (GS 7) than less aggressive tumors (GS 6) for three exon 3 CpG sites (for CpG 212 (chr8:128753145), median \% DNA methylation for GS 6 group $=89.7 \%$; median for GS 7 group $=85.8 \%$; $p$-value $=9.4 \times 10^{-4}$ (Figure 2)) We also observed a similar result for another exon 3 CpG site, CpG 213 (chr8:128753151), which approached statistical significance $(p=0.072)$ (Figure 2). For these four $\mathrm{CpG}$ sites, the median difference between the GS groups ranged from 3.7 to 4.1 percentage points. We observed no significant differences by GS for the two CpG sites evaluated in the TCGA dataset ( $p>0.05$ for both) (Figure A1 in Appendix A). Among the CpG sites that displayed a significant overall association with GS, we observed some evidence of a stronger association between lower DNA methylation at CpG 212 (chr8:128753145) and higher GS for African American (OR $=1.23,95 \%$ CI: $1.04-1.45)$ than Caucasian men (OR $=1.07,95 \%$ CI: $1.00-1.15$; $p$-interaction $=0.15$; Table 3 ). 

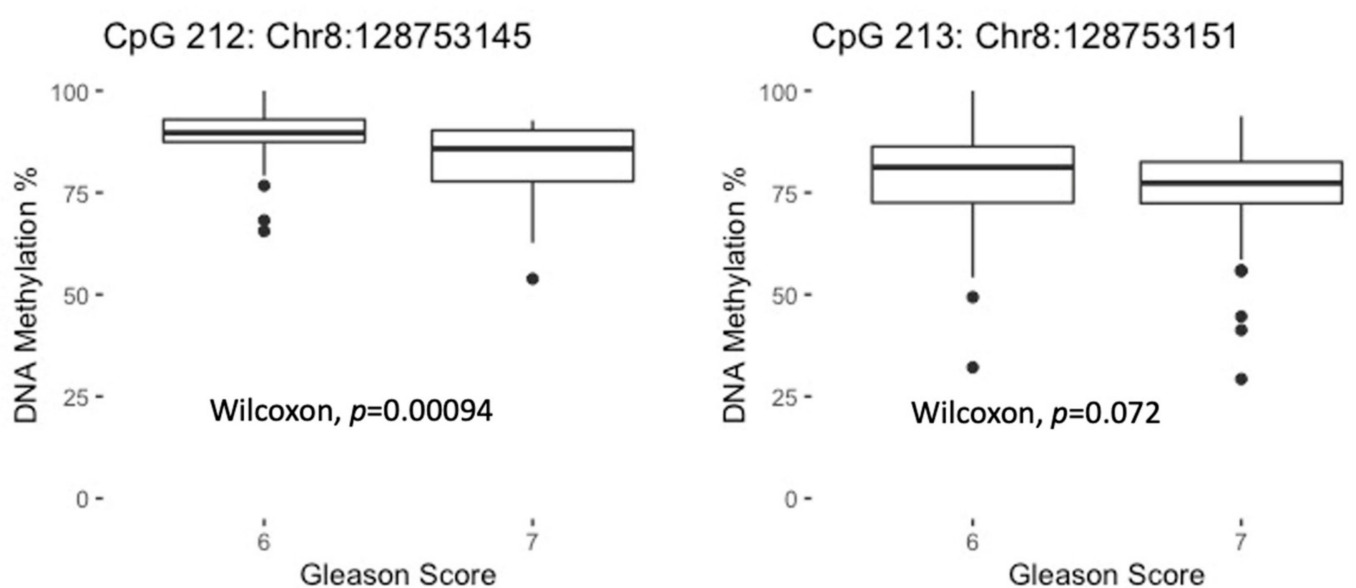

CpG 216: Chr8:128753200

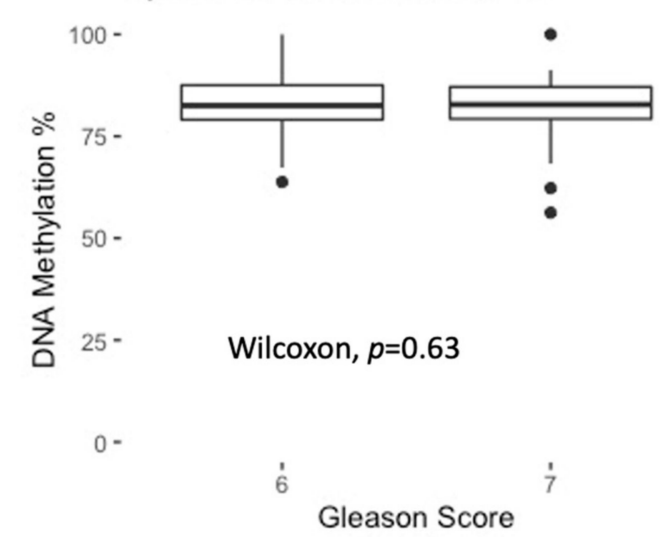

$$
100-
$$

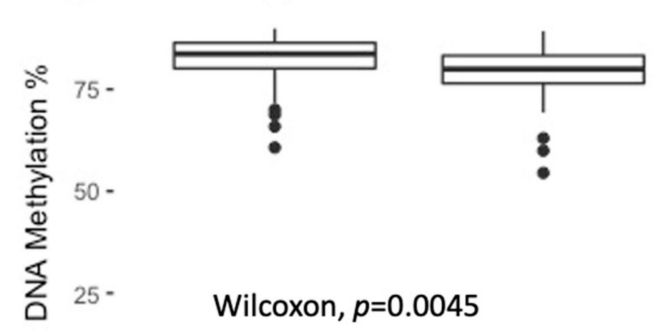

$0-$
Gleason Score

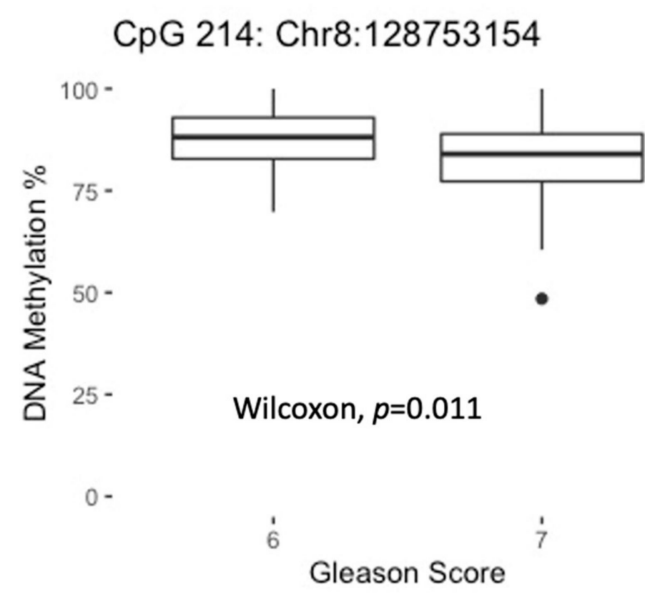

CpG 217: Chr8:128753221

$100-$

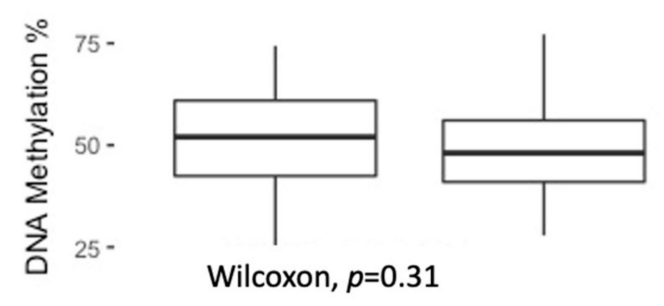

0-

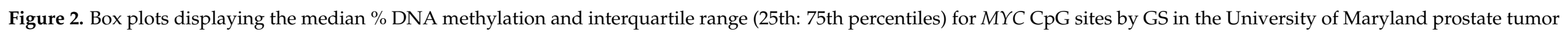
samples $(n=89)$. 
Table 3. Association between decreasing tumor MYC CpG site DNA methylation and tumor aggressiveness (GS 7 vs. 6), overall and by race in the University of Maryland samples ${ }^{\mathrm{a}}$.

\begin{tabular}{|c|c|c|c|c|}
\hline $\begin{array}{l}\text { Decreasing DNA Methylation } \\
\text { (GRCH37/hg19 Coordinate) }\end{array}$ & $\begin{array}{l}\text { Overall, } n=89 \\
\text { OR }(95 \% \text { CI })\end{array}$ & $\begin{array}{c}\text { African American, } n=43 \\
\text { OR }(95 \% \text { CI })\end{array}$ & $\begin{array}{l}\text { Caucasian, } n=46 \\
\text { OR }(95 \% \text { CI })\end{array}$ & $p$-int ${ }^{b}$ \\
\hline CpG 212 (Chr8:128753145) & $1.10(1.03-1.18)$ & $1.23(1.04-1.45)$ & $1.07(1.00-1.15)$ & 0.15 \\
\hline CpG 213 (Chr8:128753151) & $1.02(0.99-1.06)$ & $1.06(0.99-1.14)$ & $1.01(0.97-1.05)$ & 0.20 \\
\hline CpG 214 (Chr8:128753154) & $1.07(1.02-1.13)$ & $1.08(0.99-1.17)$ & $1.07(1.00-1.14)$ & 0.87 \\
\hline CpG 215 (Chr8:128753187) & $1.03(0.97-1.09)$ & $1.09(0.98-1.20)$ & $1.00(0.94-1.07)$ & 0.19 \\
\hline CpG 216 (Chr8:128753200) & $1.08(1.01-1.16)$ & $1.15(0.99-1.32)$ & $1.06(0.98-1.15)$ & 0.36 \\
\hline CpG 217 (Chr8:128753221) & $1.01(0.98-1.04)$ & $1.01(0.96-1.06)$ & $1.01(0.97-1.06)$ & 0.99 \\
\hline Across all 6 sites & $1.01(1.00-1.02)$ & $1.01(1.00-1.02)$ & $1.01(0.99-1.03)$ & 0.89 \\
\hline
\end{tabular}

Abbreviations: CI, confidence interval; GS, Gleason score; OR, odds ratio. ${ }^{a}$ From logistic regression model (separate model for each CpG site) with decreasing DNA methylation at the CpG site modeled continuously; statistically significant results $(p<0.05)$ are shown in bold. ${ }^{\mathrm{b}} p$-interaction from cross-product term between the $\mathrm{CpG}$ site and race in logistic regression model; $p$-interaction values $<0.20$ were considered noteworthy.

\subsection{RNA Expression Tumor-Normal Differences and Differences by GS in Prostate Tumor Tissue}

We evaluated differences in the log2-transformed RNA expression levels by tumor/normal sample status for 22 TCs for MYC and other genes/ncRNAs within $1 \mathrm{Mb}$ of MYC using paired tumor-normal prostate tissue samples from the 100 University of Maryland patients (Table 4). Five genes or ncRNAs were significantly upregulated in tumor compared to normal prostate tissue samples, including MYC, PRNCR1, RP11-382A18.3, POU5F1B and RNU4-25P, whereas one long non-coding RNA (lncRNA), RP11-255B23.1, was significantly downregulated in tumor compared to normal prostate tissue $(p<0.05)$. Median tumor-normal differences in expression tended to be similar between Caucasian and African American men (data not presented). Among the 100 tumor tissue samples, only two of the genes/ncRNAs evaluated displayed differential expression between GS 6 and GS 7 samples, which included CCAT1 and RNU4-25P (Table 4). For CCAT1, the median $\log 2$-transformed expression level (IQR) was $3.5(3.3,3.9)$ for the GS 6 group and 3.2 $(3.0,3.6)$ for the GS 7 group ( $p$-value $\left.=1.5 \times 10^{-3}\right)$; for RNU4-25P, the median log2-transformed level (IQR) was $5.8(5.5,6.2)$ for the GS 6 group and $5.3(4.9,5.6)$ for the GS 7 group ( $p$-value $=3.6 \times 10^{-5}$; Table 4). Notably, RNU4-25P also showed a significant interaction with race with respect to GS ( $p$-interaction $=5.6 \times 10^{-3}$ ), such that there was a significant association between tumor RNU4-25P expression and GS among Caucasian men, but not African American men (data not presented). 


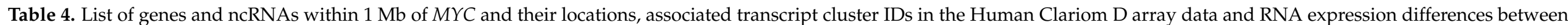
paired tumor and normal prostate tissue samples and between GS 6 and GS 7 prostate tumor samples from the University of Maryland.

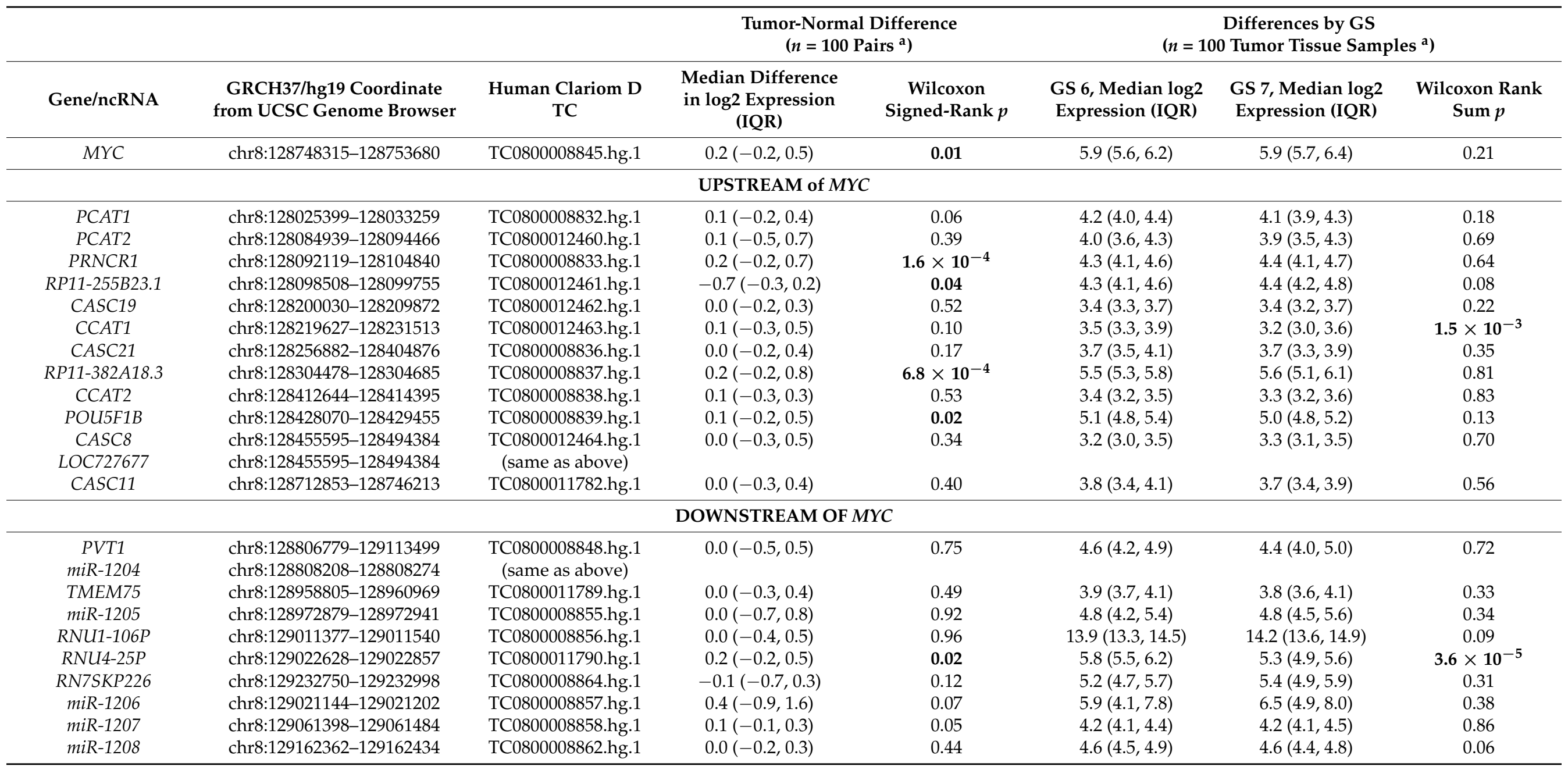

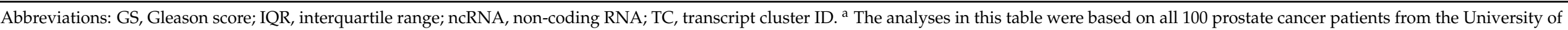
Maryland Medical Center since there was no missing RNA expression data for the TCs of interest; statistically significant $p$-values $(p<0.05)$ are shown in bold. 


\subsection{Prostate tumor MYC DNA methylation and RNA expression in prostate tumor tissue}

When we evaluated prostate tumor MYC DNA methylation in relation to RNA expression in prostate tumor tissue in the University of Maryland samples, we did not observe a significant association between any of the six CpG sites and MYC expression (data not shown). Our top findings ( $p \leq 0.05$ ) suggested inverse associations between MYC DNA methylation and expression of two lncRNAs at chromosome 8q24, PRNCR1 and CASC11, and a positive association between MYC DNA methylation and miR-1206 expression (Table 5). Notably, the association between DNA methylation at CpG 216 (chr8:128753200) and PRNCR1 expression remained statistically significant after adjustment for multiple comparisons $(\beta=-0.022$, s.e. $=0.007$, $p$-value $=2.0 \times 10^{-3}, q$-value $=0.04 ;$ Table 5 ). The effect size and direction of the associations remained similar when we restricted our analysis to the 56 prostate tumor samples with the highest quality (Positive vs. Negative AUC > 0.7) (data not shown). The remaining genes and ncRNAs evaluated were not significantly associated with MYC DNA methylation $(p>0.05)$.

Table 5. Top hits for MYC DNA methylation and RNA expression in prostate tumor tissue $(p \leq 0.05), n=89$ tumor tissue samples from the University of Maryland.

\begin{tabular}{|c|c|c|c|c|}
\hline Non-coding RNA & Description & $\begin{array}{l}\text { Coordinates } \\
\text { (GRCh37/hg19) }\end{array}$ & $\begin{array}{l}\text { MYC CpG Site and } \\
\text { Position (hg19) }\end{array}$ & $\begin{array}{c}\text { Linear regression } \beta \text { (s.e. }) \\
\quad p \text {-Value }(q \text {-Value })^{a}\end{array}$ \\
\hline PRNCR1 & $\begin{array}{c}\text { prostate cancer } \\
\text { associated } \\
\text { non-coding RNA } 1\end{array}$ & $\begin{array}{l}\text { chr8:128092119- } \\
128104840\end{array}$ & $\begin{array}{c}\text { CpG } 216 \\
\text { (chr8:128753200) } \\
\text { CpG 217 } \\
\text { (chr8:128753221) }\end{array}$ & $\begin{array}{c}\beta=-0.022(0.007) \\
p=\mathbf{2 . 0} \times \mathbf{1 0}^{-3}(q=\mathbf{0 . 0 4}) \\
\beta=-0.0094(0.0039) \\
p=\mathbf{0 . 0 2}(q=0.20)\end{array}$ \\
\hline CASC11 & $\begin{array}{l}\text { cancer susceptibility } \\
\text { candidate } 11 \\
\text { (non-protein coding), } \\
\text { transcript variant } 2\end{array}$ & $\begin{array}{l}\text { chr8:128712853- } \\
128746213\end{array}$ & $\begin{array}{c}\text { CpG } 212 \\
\text { (chr8:128753145) } \\
\text { CpG 217 } \\
\text { (chr8:128753221) }\end{array}$ & $\begin{array}{c}\beta=-0.011(0.005) \\
p=0.05(q=0.59) \\
\beta=-0.010(0.003) \\
p=\mathbf{4 . 1} \times \mathbf{1 0}^{-3}(q=0.09)\end{array}$ \\
\hline$m i R-1206$ & microRNA 1206 & $\begin{array}{c}\text { chr8:129021144- } \\
129021202\end{array}$ & $\begin{array}{c}\text { CpG } 212 \\
\text { (chr8:128753145) }\end{array}$ & $\begin{array}{c}\beta=0.053(0.025) \\
p=0.03(q=0.59)\end{array}$ \\
\hline
\end{tabular}

a Bolding denotes statistical significance at the 0.05 level; $q$-values correspond to the false discovery rate after multiple comparison adjustment (22 tests for each CpG site) using the Benjamini and Hochberg approach.

\section{Discussion}

Based on the importance of the 8q region and the $M Y C$ gene in prostate carcinogenesis/progression [13,40], we investigated the role of MYC DNA methylation (six CpG sites spanning from exon 3 to the $3^{\prime}$ UTR) in prostate tumor tissue from African American and Caucasian prostate cancer patients who underwent radical prostatectomy at the University of Maryland Medical Center. Comparing MYC DNA methylation between paired tumor-normal prostate tissue samples from the same men, we found lower DNA methylation in the tumor compared to the paired normal samples for all six CpG sites evaluated, suggesting that these may represent somatic alterations in prostate tissue. Similar patterns were observed for the two nearby $\mathrm{CpG}$ sites in exon 3 that were evaluated in TCGA. Interestingly, we also observed lower MYC DNA methylation for more aggressive (GS 7) compared to less aggressive (GS 6) tumors for several exon $3 \mathrm{CpG}$ sites. When we incorporated RNA expression data in prostate tumor tissue, we observed significant inverse associations between tumor MYC DNA methylation and expression of the lncRNAs PRNCR1 and CASC11, and a significant positive association with miR-1206 expression. Notably, our finding of an association between CpG 216 (chr8:128753200), one of the CpG sites that displayed a significant association with GS, and PRNCR1 expression also remained significant after adjustment for multiple comparisons. We did not observe evidence of an association between MYC DNA methylation at any of the CpG sites evaluated and MYC expression. 
A number of epigenome-wide studies have compared DNA methylation at specific CpG sites across the genome between prostate tumor and normal tissue [41-51], with a smaller number of epigenome-wide studies comparing DNA methylation in prostate tissue with respect to GS [52-54]. In these studies, MYC was not among the top hits, but few, if any, evaluated the specific $\mathrm{CpG}$ sites that we evaluated in the present study. For example, most of the previous studies, including TCGA, used array-based technologies such as the Illumina HumanMethylation450 BeadChip that did not cover these specific CpG sites. Another group that used MethylPlex technology with massively parallel sequencing evaluated MYC in prostate tumor tissue, but focused on the promoter region and did not evaluate exon 3 [42]. Thus, to our knowledge, our study is one of the first to study these specific MYC CpG sites in prostate tissue. Exon 3 in MYC is highly conserved across species, and we previously reported a variety of characteristics that are common to transcriptional regulatory regions within $2 \mathrm{~kb}$ of the MYC exon $3 \mathrm{CpG}$ sites in various prostate cancer cell lines using ENCODE data, which included DNaseI HS peaks, histone methylation and acetylation marks and TFBS for ETV1 and TCF7L2 [28]. Another study using ENCODE data also provided evidence of CHD2 and CTCF transcription factor ChIP-seq clusters nearby MYC [55]. CTCF is a multifunctional transcription factor involved in gene expression and gene regulation, and CTCF binding is highly sensitive to DNA methylation [55]. A previous study found lower MYC exon 3 DNA methylation in human myeloma cell lines when compared with normal lymphocytes, which correlated with increased expression [30]. Moreover, hypomethylation at MYC exon 3 in colorectal tissue was shown to be associated with progression from normal tissue to metastatic disease [31]. Although these latter studies did not focus on prostate cancer, they implicate a potential role of MYC exon 3 hypomethylation in the development or progression of cancer, which is consistent with the directions of our findings with regard to prostate tumor-normal tissue differences and differences by GS in prostate tumor tissue.

Although the results should be interpreted cautiously due to relatively small numbers, it is interesting that we observed some evidence of a stronger association for MYC DNA methylation at CpG 212 (chr8:128753145) and GS for African American than Caucasian men. Specifically, while the direction of the association was consistent for the two race groups, the association achieved statistical significance in African American men, but was slightly smaller in magnitude and borderline significant in Caucasian men. Investigations of genetic susceptibility loci at 8q24 in the African Ancestry Prostate Cancer GWAS Consortium identified several loci that were specific to African American men, suggesting the potential for different mechanisms at 8q24 contributing to prostate cancer for African American men when compared with men of other ancestries [10]. Our findings, although warranting replication with larger sample sizes, support the need for continued investigation into the potential differing roles of the $8 \mathrm{q} 24$ locus in prostate cancer by race/ancestry.

While the present study using prostate tissue among men with prostate cancer and our previous case-control study using pre-diagnostic peripheral blood DNA are not directly comparable due to differences in study design and the timing and type of samples, we note that the direction of association between MYC DNA methylation and aggressive prostate cancer observed in the present study was opposite to that reported in our previous study [28]. The differences in our findings may be due, in part, to differences in DNA methylation by tissue type as it is well established that DNA methylation displays distinct patterns by tissue [56], and may also be due in part to changes in DNA methylation over time due to the carcinogenic process [57]. We observed clear differences in DNA methylation between normal and tumor tissue in this study, suggesting that a somatic alteration occurred. We would not expect DNA methylation patterns in pre-diagnostic lymphocyte DNA to reflect somatic DNA methylation alterations in prostate tissue, such as those identified by our present study.

In the present study, we had the advantage of being able to incorporate RNA expression data so we could investigate the potential function of alterations in MYC DNA methylation in prostate tissue in the context of RNA expression modulation. Previous re- 
search demonstrated the importance of $M Y C$ promoter methylation and signaling in the regulation of $m i R-27 a-5 p$ in prostate cancer [58], providing impetus for further study of MYC DNA methylation with regard to other genes/ncRNAs. Our top associations $(p<0.05)$ for MYC DNA methylation and RNA expression included inverse associations with PRNCR1 and CASC11 and, notably, the association between MYC DNA methylation at CpG 216 (chr8:128753200) and PRNCR1 remained significant after adjustment for multiple comparisons. Prostate cancer-associated non-coding RNA 1 (PRNCR1) is a lncRNA that has been proposed to contribute to prostate carcinogenesis by increasing the looping of androgen receptor (AR)-bound enhancers to AR target genes and, in turn, increasing cell proliferation [59]. Previous studies have observed up-regulation of PRNCR1 expression in prostate cancer cell lines and in the precursor lesion prostatic intraepithelial neoplasia [15]. Consistent with these findings, we also observed higher expression of PRNCR1 in prostate tumor compared to paired normal tissue samples in our study. Cancer susceptibility candidate 11 (CASC11) is another IncRNA that has been shown to be overexpressed in prostate cancer [16], although we did not detect a difference in CASC11 expression between the tumor and normal samples in our study. Our observations of lower MYC DNA methylation in tumor tissue and inverse MYC methylation associations with PRNCR1 and CASC11 thus appear to be in line with the biology of these ncRNAs (i.e., if $M Y C$ methylation is lower in tumor than normal tissue and inversely associated with these lncRNAs, then we would expect to see increased expression of these lncRNAs in tumor, as we and others have observed). Our other top finding $(p<0.05)$ regarding MYC DNA methylation and RNA expression was a positive association between MYC methylation and miR-1206 expression, although this finding did not persist after multiple comparison adjustment. MiR-1206 is part of a lncRNA transcript of the PVT1 gene and, notably, was found to have lower expression in prostate tumor compared to normal tissue in a previous study [60]. The directions of our observed associations (i.e., lower MYC methylation in prostate tumor than normal tissue and positive association between MYC methylation and miR-1206 expression) thus also appear to fit with the biology of miR-1206.

Our finding of no association between MYC DNA methylation and MYC expression in prostate tumor suggests that if $M Y C$ methylation influences the expression of the above ncRNAs, then it is unlikely to be through an effect on MYC expression. Instead, it is possible that there is a direct effect of $M Y C$ methylation on expression of the ncRNAs. There is some plausibility for this hypothesis based on examples of long-range interactions at chromosome 8q24, which influence gene expression, for example, an interaction between rs378854 (a SNP in linkage disequilibrium with rs620861, an established prostate cancer susceptibility SNP) and PVT1 [61]. While our findings provide some clues about the potential function of alterations in MYC methylation, it is also possible that DNA methylation alterations in this region do not directly affect RNA expression, and that these are independent changes that are both correlated with the carcinogenetic process. Further research is needed in in vitro or animal models to assess if there is a causal effect of MYC DNA methylation alterations on RNA expression at 8q24 and to clarify the underlying mechanisms.

There were several limitations in our study. Our overall sample size was relatively small and we only included radical prostatectomy patients with a GS of 6 or 7. It would have been preferable to compare patients with GS of 8 or higher (instead of GS 7) to those with GS 6 for better contrast (which we hypothesize would have led to larger effect sizes); however, there were relatively few patients with a GS of 8 or higher in our patient population. We expect this may be due, in part, to the fact that we drew our study participants from radical prostatectomy patients and this surgery is predominantly indicated for patients with localized disease, who usually have a lower GS. To help reduce this limitation, we focused on tumor regions with a Gleason pattern 4 where possible for patients with GS 7 to increase the contrast with our comparison group (GS 6, typically involving pattern 3 only). We only evaluated DNA methylation for a small number of CpG sites in MYC, for which we had a priori rationale; future studies would benefit from a more comprehensive investigation of DNA methylation across the $M Y C$ genome, as well as replication of the 
results for the specific $\mathrm{CpG}$ sites of interest in an independent population. While inclusion of the TCGA data allowed us to evaluate two CpG sites nearby, we cannot directly compare our results from the University of Maryland samples with TCGA because different CpG sites were evaluated (the sites evaluated in the University of Maryland samples were not covered by the array used in TCGA) and the extent of correlation between the CpG sites is unknown. There were also some ncRNAs that we were unable to evaluate in our analysis because they were not covered on the Clariom D array; however, we were able to evaluate expression for most genes and ncRNAs within $1 \mathrm{Mb}$ of $M Y C$, providing insight regarding potential mechanisms. We were also unable to investigate the main effect of race on MYC DNA methylation due to our study design, such that we fixed the distribution of GS within each race group, which may have made the distribution of DNA methylation more similar between the race groups as well. However, the rationale for this design is that it maximized our power to separately evaluate the association between MYC DNA methylation and GS by race, which was one of our study aims.

Our study also had several strengths, including the integration of epigenetic and transcriptomic data. By incorporating RNA expression data from the Human Clariom $\mathrm{D}$ array, we were able to evaluate the association between MYC DNA methylation and RNA expression for MYC and a variety of other genes and ncRNAs of interest nearby. Other strengths were: (1) our diverse study population, which allowed for separate study of African American men, who bear a disproportionate burden of aggressive prostate cancer and prostate cancer mortality, but have been traditionally understudied; (2) use of GS as an outcome, which is an established intermediate prognostic marker for prostate cancer [29]; (3) centralized pathology review of all samples by a single pathologist; and (4) use of pyrosequencing, a reproducible and quantitative method in detecting inter-individual differences in DNA methylation.

In summary, focusing on CpG sites from exon 3 to the $3^{\prime}$ UTR of $M Y C$, our results suggested lower MYC DNA methylation in prostate tumor compared to paired normal prostate tissue, and lower exon 3 DNA methylation for more aggressive compared to less aggressive tumors. Although numbers were relatively small, we also noted some evidence of a stronger association for African American than Caucasian men for one of the CpG sites that displayed a significant overall association with GS, highlighting the importance of continued investigation of prostate cancer biomarkers separately by race. Incorporation of RNA expression data allowed for initial investigation into the potential function of these DNA methylation alterations. More research is needed to replicate these findings and further explore the relationship of MYC DNA methylation with aggressive prostate cancer, including the function, timing and stability of these alterations over the course of prostate carcinogenesis, and their potential role as passengers or drivers. Further research is also needed to elucidate differences in prostate tumor biology by race/ancestry, which may help provide insight into differences in disease aggressiveness and disparities in prostate cancer outcomes. 
Author Contributions: Conceptualization, K.H.B., A.B., A.H. and S.I.B.; formal analysis, K.H.B., K.M., P.A.E., D.W., Y.Z. and S.I.B.; funding acquisition, K.H.B.; investigation, G.R., K.C., J.Y., L.Y., M.P. and A.M.; methodology, K.H.B., D.W., J.S., A.C., N.A., Jr., L.Y., M.P., A.M., Y.Z., S.M.B., A.B., A.H. and S.I.B.; supervision, K.H.B., J.S., A.C., N.A., Jr., L.Y., A.B. and S.I.B.; visualization, K.M., D.W., Y.Z. and S.M.B.; writing-original draft, K.H.B.; writing-review and editing, K.H.B., K.M., P.A.E., D.W., J.S., G.R., A.C., K.C., N.A., Jr., J.Y., L.Y., M.P., A.M., Y.Z., S.M.B., A.B., A.H. and S.I.B. All authors read and agreed to the submitted version of the manuscript.

Funding: This work was supported by funds through the Maryland Department of Health's Cigarette Restitution Fund Program and by a Collaborative Program Award (competitive seed grant) from the University of Maryland Marlene and Stewart Greenebaum Comprehensive Cancer Center to K.H.B. This work was also supported by funds through the National Cancer Institute (NCI)-Cancer Center Support Grant (CCSG)-P30CA134274. K.H.B. is supported by K07 CA230182 from the NCI. S.I.B., D.W. and J.S. are supported by the Intramural Research Program of the Division of Cancer Epidemiology and Genetics at the NCI. A.H. is supported by VA Merit Review Award (I01 BX000545, Medical Research Service, Dept of Veterans Affairs).

Acknowledgments: We acknowledge the contributions from the Pathology, Genomics and Biostatistics Shared Services at the University of Maryland Marlene and Stewart Greenebaum Comprehensive Cancer Center to this project.

Conflicts of Interest: L.Y., M.P. and A.M. are employed by EpigenDx, Inc, and L.Y. is the major stockholder of EpigenDx. All other authors declare no conflicts of interest. The funders had no role in the design of the study; in the collection, analyses, or interpretation of data; in the writing of the manuscript, or in the decision to publish the results. 


\section{Appendix A}

Table A1. MYC Pyrosequencing Assay Target Sequences; green highlight denotes the CpG sites covered in the present study.

\begin{tabular}{|c|c|c|c|}
\hline Assay ID & Genomic Target Sequence & Bisulfite Converted Target Sequence & Pyrosequencing Dispensation Order \\
\hline ADS3573-FS & $\begin{array}{l}\text { ACTTGTTG CG GAAA CG A CG AGAACAG } \\
\text { TTGAAACACAAACTTGAACAGCTA CG G } \\
\text { AACTCTTGTG CG TAAGGAAAAGTAAGG } \\
\text { AAAA CG ATTCCTTCTAACAGAAATG }\end{array}$ & $\begin{array}{l}\text { ATTTGTTG YG GAAA YG A YG AGAATA } \\
\text { GTTGAAATATAAATTTGAATAGTTA } \\
\text { YG GAATTTTTGG YG TAAGGAAAAG } \\
\text { TAAGGAAAA YG ATTTTTTTTAATAG } \\
\text { AAATG }\end{array}$ & $\begin{array}{l}\text { ACTGTAGTCGATCGATCGAGATCAGTGA } \\
\text { TCATCACTGATCAGCTGATCGACTCTGT } \\
\text { GTCGTCAGAAGTCAGATCGA }\end{array}$ \\
\hline ADS3573-FS2 & $\begin{array}{l}\text { AACTTGAACAGCTA CG GAACTCTTGTG } \\
\text { CG TAAGGAAAAGTAAGGAAAA CG ATT } \\
\text { CCTTCTAACAGAAATGTCCTGA }\end{array}$ & $\begin{array}{l}\text { AATTTGAATAGTTA YG GAATTTTTGT } \\
\text { G YG TAAGGAAAAGTAAGGAAAA YG } \\
\text { ATTTTTTTTAATAGAAATGTTTTGA }\end{array}$ & $\begin{array}{l}\text { ACTGACTAGCTGATCGATCTGTAGTCGT } \\
\text { AGAAGTAGAATCGA }\end{array}$ \\
\hline
\end{tabular}

cg00163372 G6 vs. G7

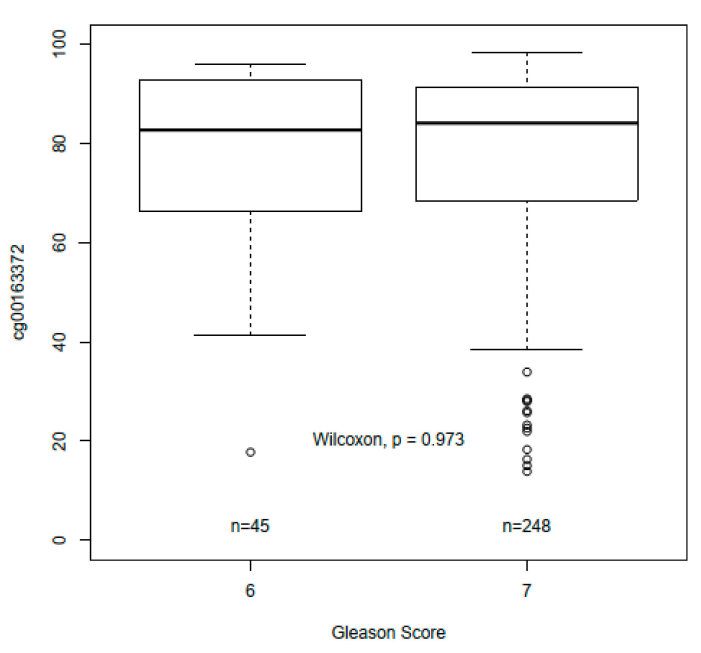

(a)

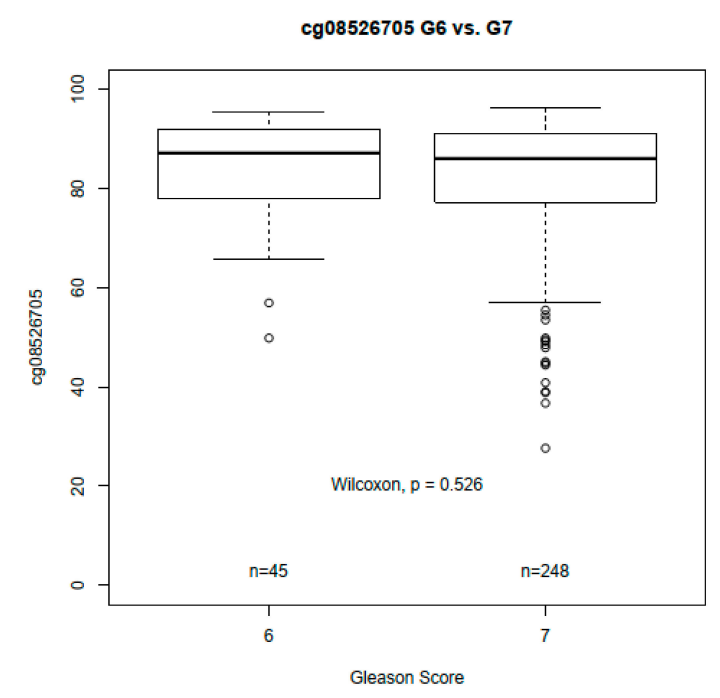

(b)

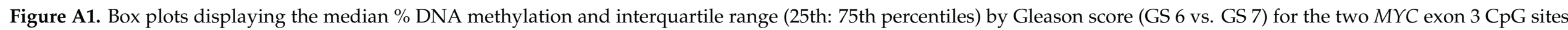
evaluated in The Cancer Genome Atlas (TCGA) data, $n=293$ prostate tumor samples: (a) cg00163372 and (b) cg08526705. 


\section{References}

1. Amundadottir, L.T.; Sulem, P.; Gudmundsson, J.; Helgason, A.; Baker, A.; Agnarsson, B.; Sigurdsson, A.; Benediktsdottir, K.R.; Cazier, J.-B.; Sainz, J.; et al. A common variant associated with prostate cancer in European and African populations. Nat. Genet. 2006, 38, 652-658. [CrossRef] [PubMed]

2. Gudmundsson, J.; Sulem, P.; Manolescu, A.; Amundadottir, L.T.; Gudbjartsson, D.; Helgason, A.; Rafnar, T.; Bergthorsson, J.T.; Agnarsson, B.; Baker, A.; et al. Genome-wide association study identifies a second prostate cancer susceptibility variant at $8 \mathrm{q} 24$. Nat. Genet. 2007, 39, 631-637. [CrossRef] [PubMed]

3. Haiman, C.; Patterson, N.; Freedman, M.L.; Myers, S.R.; Pike, M.C.; Waliszewska, A.; Neubauer, J.; Tandon, A.; Schirmer, C.; McDonald, G.J.; et al. Multiple regions within 8q24 independently affect risk for prostate cancer. Nat. Genet. 2007, 39, 638-644. [CrossRef] [PubMed]

4. Yeager, M.; Orr, N.; Hayes, R.B.; Jacobs, K.B.; Kraft, P.; Wacholder, S.; Minichiello, M.J.; Fearnhead, P.; Yu, K.; Chatterjee, N.; et al. Genome-wide association study of prostate cancer identifies a second risk locus at 8q24. Nat. Genet. 2007, 39, 645-649. [CrossRef]

5. Eeles, R.A.; Kote-Jarai, Z.; Giles, G.G.; Al Olama, A.A.; Guy, M.; Jugurnauth, S.K.; Mulholland, S.; Leongamornlert, D.A.; Edwards, S.M.; Field, H.I.; et al. Multiple newly identified loci associated with prostate cancer susceptibility. Nat. Genet. 2008, 40, 316-321. [CrossRef]

6. Thomas, G.; Jacobs, K.B.; Yeager, M.; Kraft, P.; Wacholder, S.; Orr, N.; Yu, K.; Chatterjee, N.; Welch, R.W.; Hutchinson, A.; et al. Multiple loci identified in a genome-wide association study of prostate cancer. Nat. Genet. 2008, 40, 310-315. [CrossRef]

7. Al Olama, A.A.; Kote-Jarai, Z.; Giles, G.G.; Guy, M.; Morrison, J.; Severi, G.; Leongamornlert, D.; Tymrakiewicz, M.; Jhavar, S.; Hopper, J.L.; et al. Multiple loci on 8q24 associated with prostate cancer susceptibility. Nat. Genet. 2009, 41, 1058-1060. [CrossRef]

8. Schumacher, F.R.; Berndt, S.I.; Siddiq, A.; Jacobs, K.B.; Wang, Z.; Lindstrom, S.; Stevens, V.L.; Chen, C.; Mondul, A.M.; Travis, R.C.; et al. Genome-wide association study identifies new prostate cancer susceptibility loci. Hum. Mol. Genet. 2011, 20, 3867-3875. [CrossRef]

9. Gudmundsson, J.; Sulem, P.; Gudbjartsson, D.F.; Masson, G.; Agnarsson, B.A.; Benediktsdottir, K.R.; Sigurdsson, A.; Magnusson, O.T.; Gudjonsson, S.A.; Magnusdottir, D.N.; et al. A study based on whole-genome sequencing yields a rare variant at 8q24 associated with prostate cancer. Nat. Genet. 2012, 44, 1326-1329. [CrossRef]

10. Han, Y.; Rand, K.A.; Hazelett, D.J.; Ingles, S.A.; Kittles, R.A.; Strom, S.S.; Rybicki, B.A.; Nemesure, B.; Isaacs, W.B.; Stanford, J.L.; et al. Prostate Cancer Susceptibility in Men of African Ancestry at 8q24. J. Natl. Cancer Inst. 2016, 108. [CrossRef]

11. Matejcic, M.; Saunders, E.J.; Dadaev, T.; Brook, M.N.; Wang, K.; Sheng, X.; Al Olama, A.A.; Schumacher, F.R.; Ingles, S.A.; Benlloch, S.; et al. Germline variation at 8q24 and prostate cancer risk in men of European ancestry. Nat. Commun. 2018, 9, 4616. [CrossRef] [PubMed]

12. Darst, B.F.; Wan, P.; Sheng, X.; Bensen, J.T.; Ingles, S.A.; Rybicki, B.A.; Nemesure, B.; John, E.M.; Fowke, J.H.; Stevens, V.L.; et al. A Germline Variant at 8q24 Contributes to Familial Clustering of Prostate Cancer in Men of African Ancestry. Eur. Urol. 2020, 78, 316-320. [CrossRef] [PubMed]

13. Koh, C.M.; Bieberich, C.J.; Van Dang, C.; Nelson, W.G.; Yegnasubramanian, S.; De Marzo, A.M. MYC and Prostate Cancer. Genes Cancer 2010, 1, 617-628. [CrossRef] [PubMed]

14. Kastler, S.; Honold, L.; Luedeke, M.; Kuefer, R.; Möller, P.; Hoegel, J.; Vogel, W.; Maier, C.; Assum, G. POU5F1P1, a putative cancer susceptibility gene, is overexpressed in prostatic carcinoma. Prostate 2009, 70. [CrossRef]

15. Chung, S.; Nakagawa, H.; Uemura, M.; Piao, L.; Ashikawa, K.; Hosono, N.; Takata, R.; Akamatsu, S.; Kawaguchi, T.; Morizono, T.; et al. Association of a novel long non-coding RNA in 8q24 with prostate cancer susceptibility. Cancer Sci. 2010, 102, $245-252$. [CrossRef]

16. Bawa, P.; Zackaria, S.; Verma, M.; Gupta, S.; Srivatsan, R.; Chaudhary, B.; Srinivasan, S. Integrative Analysis of Normal Long Intergenic Non-Coding RNAs in Prostate Cancer. PLoS ONE 2015, 10, e0122143. [CrossRef]

17. Zheng, J.; Zhao, S.; He, X.; Zheng, Z.; Bai, W.; Duan, Y.; Cheng, S.; Wang, J.; Liu, X.; Zhang, G. The up-regulation of long noncoding RNA CCAT2 indicates a poor prognosis for prostate cancer and promotes metastasis by affecting epithelial-mesenchymal transition. Biochem. Biophys. Res. Commun. 2016, 480, 508-514. [CrossRef]

18. Jia, L.; Landan, G.; Pomerantz, M.; Jaschek, R.; Herman, P.; Reich, D.; Yan, C.; Khalid, O.; Kantoff, P.W.; Oh, W.K.; et al. Functional Enhancers at the Gene-Poor 8q24 Cancer-Linked Locus. PLoS Genet. 2009, 5, e1000597. [CrossRef]

19. Ahmadiyeh, N.; Pomerantz, M.M.; Grisanzio, C.; Herman, P.; Jia, L.; Almendro, V.; He, H.H.; Brown, M.; Liu, X.S.; Davis, M.; et al. 8 q24 prostate, breast, and colon cancer risk loci show tissue-specific long-range interaction with MYC. Proc. Natl. Acad. Sci. USA 2010, 107, 9742-9746. [CrossRef]

20. Sotelo, J.; Esposito, D.; Duhagon, M.A.; Banfield, K.; Mehalko, J.; Liao, H.; Stephens, R.M.; Harris, T.J.R.; Munroe, D.J.; Wu, X. Long-range enhancers on 8q24 regulate c-Myc. Proc. Natl. Acad. Sci. USA 2010, 107, 3001-3005. [CrossRef]

21. Du, M.; Yuan, T.; Schilter, K.F.; Dittmar, R.; MacKinnon, A.; Huang, X.; Tschannen, M.; Worthey, E.; Jacob, H.; Xia, S.; et al. Prostate cancer risk locus at 8q24 as a regulatory hub by physical interactions with multiple genomic loci across the genome. Hum. Mol. Genet. 2014, 24, 154-166. [CrossRef] [PubMed]

22. Cai, M.; Kim, S.; Wang, K.; Farnham, P.J.; Coetzee, G.A.; Lu, W. 4C-seq revealed long-range interactions of a functional enhancer at the 8q24 prostate cancer risk locus. Sci. Rep. 2016, 6, 22462. [CrossRef] [PubMed] 
23. Esteller, M.; Herman, J.G. Cancer as an epigenetic disease: DNA methylation and chromatin alterations in human tumours. J. Pathol. 2002, 196, 1-7. [CrossRef] [PubMed]

24. Massie, C.E.; Mills, I.; Lynch, A.G. The importance of DNA methylation in prostate cancer development. J. Steroid Biochem. Mol. Biol. 2017, 166, 1-15. [CrossRef] [PubMed]

25. Kang, G.H.; Lee, S.; Lee, H.J.; Hwang, K.S. Aberrant CpG island hypermethylation of multiple genes in prostate cancer and prostatic intraepithelial neoplasia. J. Pathol. 2004, 202, 233-240. [CrossRef] [PubMed]

26. Yegnasubramanian, S.; Kowalski, J.; Gonzalgo, M.L.; Zahurak, M.; Piantadosi, S.; Walsh, P.C.; Bova, G.S.; De Marzo, A.M.; Isaacs, W.; Nelson, W.G. Hypermethylation of CpG Islands in Primary and Metastatic Human Prostate Cancer. Cancer Res. 2004, 64, 1975-1986. [CrossRef]

27. Yegnasubramanian, S.; Haffner, M.C.; Zhang, Y.; Gurel, B.; Cornish, T.C.; Wu, Z.; Irizarry, R.A.; Morgan, J.; Hicks, J.; Deweese, T.L.; et al. DNA Hypomethylation Arises Later in Prostate Cancer Progression than CpG Island Hypermethylation and Contributes to Metastatic Tumor Heterogeneity. Cancer Res. 2008, 68, 8954-8967. [CrossRef]

28. Barry, K.H.; Moore, L.; Sampson, J.N.; Koutros, S.; Yan, L.; Meyer, A.; Reddy, M.; Oler, A.J.; Cook, M.B.; Fraumeni, J.F., Jr.; et al. Prospective study of DNA methylation at chromosome 8q24 in peripheral blood and prostate cancer risk. Br. J. Cancer 2017, 116, 1470-1479. [CrossRef]

29. Catalona, W.J.; Smith, D.S. 5-Year Tumor Recurrence Rates after Anatomical Radical Retropubic Prostatectomy for Prostate Cancer. J. Urol. 1994, 152, 1837-1842. [CrossRef]

30. Ohtsuki, T.; Nishitani, K.; Hatamochi, A.; Yavvata, Y.; Namba, M. Analysis of methylation in the $c-M Y C$ gene in five human myeloma cell lines. Br. J. Haematol. 1991, 77, 172-179. [CrossRef]

31. Sharrard, R.M.; Royds, J.; Rogers, S.N.; Shorthouse, A.J. Patterns of methylation of the $c$-myc gene in human colorectal cancer progression. Br. J. Cancer 1992, 65, 667-672. [CrossRef] [PubMed]

32. Siegel, R.L.; Miller, K.D.; Jemal, A. Cancer statistics, 2020. CA Cancer J. Clin. 2020, 70, 7-30. [CrossRef] [PubMed]

33. Bhardwaj, A. Racial disparities in prostate cancer a molecular perspective. Front. Biosci. 2017, 22, 772-782. [CrossRef] [PubMed]

34. Khani, F.; Mosquera, J.M.; Park, K.; Blattner, M.; O’Reilly, C.; Macdonald, T.Y.; Chen, Z.; Srivastava, A.; Tewari, A.K.; Barbieri, C.E.; et al. Evidence for Molecular Differences in Prostate Cancer between African American and Caucasian Men. Clin. Cancer Res. 2014, 20, 4925-4934. [CrossRef]

35. Singh, R. Molecular basis for prostate cancer racial disparities. Front. Biosci. 2017, 22, 428-450. [CrossRef]

36. Barry, K.H.; Moore, L.E.; Sampson, J.; Yan, L.; Meyer, A.; Oler, A.J.; Chung, C.C.; Wang, Z.; Yeager, M.; Amundadottir, L.T.; et al. DNA methylation levels at chromosome 8q24 in peripheral blood are associated with 8q24 cancer susceptibility loci. Cancer Prev. Res. 2014, 7, 1282-1292. [CrossRef]

37. NetAffx. Available online: https://www.affymetrix.com/analysis/index.affx (accessed on 21 June 2020).

38. Newman, A.M.; Steen, C.B.; Liu, C.L.; Gentles, A.J.; Chaudhuri, A.A.; Scherer, F.; Khodadoust, M.S.; Esfahani, M.S.; Luca, B.A.; Steiner, D.; et al. Determining cell type abundance and expression from bulk tissues with digital cytometry. Nat. Biotechnol. 2019, 37, 773-782. [CrossRef]

39. Benjamini, Y.; Hochberg, Y. Controlling the false discovery rate: A practical and powerful approach to multiple testing. J. R. Stat. Soc. Ser. B 1995, 57, 289-300. [CrossRef]

40. Ribeiro, F.R.; Jerónimo, C.; Henrique, R.; Fonseca, D.; Oliveira, J.; Lothe, R.; Teixeira, M.R. 8q Gain Is an Independent Predictor of Poor Survival in Diagnostic Needle Biopsies from Prostate Cancer Suspects. Clin. Cancer Res. 2006, 12, 3961-3970. [CrossRef]

41. Devaney, J.M.; Wang, S.; Funda, S.; Long, J.; Taghipour, D.J.; Tbaishat, R.; Furbert-Harris, P.; Ittmann, M.; Kwabi-Addo, B. Identification of novel DNA-methylated genes that correlate with human prostate cancer and high-grade prostatic intraepithelial neoplasia. Prostate Cancer Prostatic Dis. 2013, 16, 292-300. [CrossRef]

42. Kim, J.H.; Dhanasekaran, S.M.; Prensner, J.R.; Cao, X.; Robinson, D.; Kalyana-Sundaram, S.; Huang, C.; Shankar, S.; Jing, X.; Iyer, M.; et al. Deep sequencing reveals distinct patterns of DNA methylation in prostate cancer. Genome Res. 2011, 21, 1028-1041. [CrossRef] [PubMed]

43. Kim, J.W.; Kim, S.-T.; Turner, A.R.; Young, T.; Smith, S.; Liu, W.; Lindberg, J.; Egevad, L.; Gronberg, H.; Isaacs, W.B.; et al. Identification of New Differentially Methylated Genes That Have Potential Functional Consequences in Prostate Cancer. PLoS ONE 2012, 7, e48455. [CrossRef] [PubMed]

44. Kim, S.J.; Kelly, W.K.; Fu, A.; Haines, K.; Hoffman, A.; Zheng, T.; Zhu, Y. Genome-wide methylation analysis identifies involvement of TNF- $\alpha$ mediated cancer pathways in prostate cancer. Cancer Lett. 2011, 302, 47-53. [CrossRef] [PubMed]

45. Kobayashi, Y.; Absher, D.M.; Gulzar, Z.G.; Young, S.R.; McKenney, J.K.; Peehl, D.M.; Brooks, J.D.; Myers, R.M.; Sherlock, G. DNA methylation profiling reveals novel biomarkers and important roles for DNA methyltransferases in prostate cancer. Genome Res. 2011, 21, 1017-1027. [CrossRef] [PubMed]

46. Kron, K.; Pethe, V.; Briollais, L.; Sadikovic, B.; Ozcelik, H.; Sunderji, A.; Venkateswaran, V.; Pinthus, J.; Fleshner, N.; Van Der Kwast, T.; et al. Discovery of Novel Hypermethylated Genes in Prostate Cancer Using Genomic CpG Island Microarrays. PLoS ONE 2009, 4, e4830. [CrossRef]

47. Luo, J.-H.; Ding, Y.; Chen, R.; Michalopoulos, G.; Nelson, J.; Tseng, G.; Yu, Y.P. Genome-Wide Methylation Analysis of Prostate Tissues Reveals Global Methylation Patterns of Prostate Cancer. Am. J. Pathol. 2013, 182, 2028-2036. [CrossRef]

48. Mahapatra, S.; Klee, E.W.; Young, C.Y.F.; Sun, Z.; Jimenez, R.E.; Klee, G.G.; Tindall, D.J.; Donkena, K.V. Global Methylation Profiling for Risk Prediction of Prostate Cancer. Clin. Cancer Res. 2012, 18, 2882-2895. [CrossRef] 
49. Kirby, M.K.; Ramaker, R.C.; Roberts, B.S.; Lasseigne, B.N.; Gunther, D.S.; Burwell, T.C.; Davis, N.S.; Gulzar, Z.G.; Absher, D.; Cooper, S.J.; et al. Genome-wide DNA methylation measurements in prostate tissues uncovers novel prostate cancer diagnostic biomarkers and transcription factor binding patterns. BMC Cancer 2017, 17, 273. [CrossRef]

50. Paziewska, A.; Dabrowska, M.; Goryca, K.; Antoniewicz, A.; Dobruch, J.; Mikula, M.; Jarosz, D.F.; Zapala, L.; Borowka, A.; Ostrowski, J. DNA methylation status is more reliable than gene expression at detecting cancer in prostate biopsy. Br. J. Cancer 2014, 111, 781-789. [CrossRef]

51. Aref-Eshghi, E.; Schenkel, L.C.; Ainsworth, P.; Lin, H.; Rodenhiser, D.I.; Cutz, J.-C.; Sadikovic, B. Genomic DNA MethylationDerived Algorithm Enables Accurate Detection of Malignant Prostate Tissues. Front. Oncol. 2018, 8, 100. [CrossRef]

52. Geybels, M.S.; Wright, J.L.; Bibikova, M.; Klotzle, B.; Fan, J.-B.; Zhao, S.; Feng, Z.; Ostrander, E.A.; Lin, D.W.; Nelson, P.S.; et al. Epigenetic signature of Gleason score and prostate cancer recurrence after radical prostatectomy. Clin. Epigenet. $2016,8,97$. [CrossRef]

53. Bhasin, J.M.; Lee, B.H.; Matkin, L.; Taylor, M.G.; Hu, B.; Xu, Y.; Magi-Galluzzi, C.; Klein, E.A.; Ting, A.H. Methylome-wide Sequencing Detects DNA Hypermethylation Distinguishing Indolent from Aggressive Prostate Cancer. Cell Rep. 2015, 13, 2135-2146. [CrossRef] [PubMed]

54. Haldrup, C.; Mundbjerg, K.; Vestergaard, E.M.; Lamy, P.; Wild, P.; Schulz, W.A.; Arsov, C.; Visakorpi, T.; Borre, M.; Høyer, S.; et al. DNA Methylation Signatures for Prediction of Biochemical Recurrence After Radical Prostatectomy of Clinically Localized Prostate Cancer. J. Clin. Oncol. 2013, 31, 3250-3258. [CrossRef] [PubMed]

55. Schuijers, J.; Manteiga, J.C.; Weintraub, A.S.; Day, D.S.; Zamudio, A.V.; Hnisz, D.; Lee, T.I.; Young, R.A. Transcriptional Dysregulation of MYC Reveals Common Enhancer-Docking Mechanism. Cell Rep. 2018, 23, 349-360. [CrossRef] [PubMed]

56. Luo, C.; Hajkova, P.; Ecker, J.R. Dynamic DNA methylation: In the right place at the right time. Science 2018, 361, 1336-1340. [CrossRef] [PubMed]

57. Barry, K.H.; Moore, L.E.; Liao, L.M.; Huang, W.-Y.; Andreotti, G.; Poulin, M.; Berndt, S.I. Prospective study of DNA methylation at LINE-1 and Alu in peripheral blood and the risk of prostate cancer. Prostate 2015, 75, 1718-1725. [CrossRef] [PubMed]

58. Barros-Silva, D.; Costa-Pinheiro, P.; Duarte, H.; Sousa, E.J.; Evangelista, A.F.; Graça, I.; Carneiro, I.; Martins, A.T.; Oliveira, J.; Carvalho, A.L.; et al. MicroRNA-27a-5p regulation by promoter methylation and MYC signaling in prostate carcinogenesis. Cell Death Dis. 2018, 9, 1-15. [CrossRef]

59. Zhang, A.; Zhang, J.; Kaipainen, A.; Lucas, J.M.; Yang, H. Long non-coding RNA: A newly deciphered "code" in prostate cancer. Cancer Lett. 2016, 375, 323-330. [CrossRef]

60. El Bezawy, R.; Cominetti, D.; Fenderico, N.; Zuco, V.; Beretta, G.L.; Dugo, M.; Arrighetti, N.; Stucchi, C.; Rancati, T.; Valdagni, R.; et al. miR-875-5p counteracts epithelial-to-mesenchymal transition and enhances radiation response in prostate cancer through repression of the EGFR-ZEB1 axis. Cancer Lett. 2017, 395, 53-62. [CrossRef]

61. Meyer, K.B.; Maia, A.-T.; O’Reilly, M.; Ghoussaini, M.; Prathalingam, R.; Porter-Gill, P.; Ambs, S.; Prokunina-Olsson, L.; Carroll, J.; Ponder, B.A.J. A Functional Variant at a Prostate Cancer Predisposition Locus at 8q24 Is Associated with PVT1 Expression. PLoS Genet. 2011, 7, e1002165. [CrossRef] 